\title{
Using Behavioral Experimentation to Understand the Social Structure of the Little Fire Ant (Wasmannia auropunctata) in Florida
}

\author{
Jacob Aron Hornfeldt, Leo Ohyama, \& Andrea Lucky \\ University of Florida
}

Faculty Mentor: Andrea Lucky, Department of Entomology \& Nematology

\begin{abstract}
Wasmannia auropunctata (little fire ant: LFA) is a small yellow ant that is native to Central and South America and has become a globally invasive species by acting as an agricultural pest in addition to being ecologically destructive in non-native regions. One trait thought to contribute to successful invasion in ants is unicoloniality, which is characterized by lack of aggression among workers and queens from different colonies. This results in colonies becoming effectively borderless, expanding as a single, massive colony across a large geographic distance. These ants are known to be unicolonial in some parts of their range, but no studies to date have assessed unicoloniality in Florida populations. To determine whether LFA populations across Florida were members of a unicolonial lineage, we carried out integration trials using 27 colonies from six sites in three Florida counties. Approximately 20 workers from different colonies were placed together in an arena; after 24 hours they were evaluated to determine whether or not they integrated. Out of a total of 42 trials, 17 (40\%) resulted in full integration and 25 $(60 \%)$ did not. Colonies that were collected within $10 \mathrm{~km}$ of each other integrated, and ants from colonies beyond that distance did not integrate. These results suggest that the little fire is not unicolonial in Florida on a large scale, but perhaps on a smaller scale. Future studies should attempt to use colonies from more counties and incorporate genetic data to determine relatedness among these ants.
\end{abstract}

Keywords: little fire ant, social structure, unicoloniality, behavior, invasive, Florida

\section{Introduction}

Wasmannia auropunctata (Roger) (the little fire ant: LFA) is a small, yellow ant native to Central and South America that has become a globally invasive species. It has become established in tropical and subtropical regions of the world including parts of the United States, Africa, Europe, Australia, and the Pacific Islands (Wetterer, 2013). In areas where the LFA is non-native, it has become a serious pest that threatens native biodiversity because of its ability to outcompete native arthropod fauna (Le Breton et al., 2003). While research on these exact impacts are limited, a study in New Caledonia found that when little fire ants are present, they reduced ant species richness and overall ant abundance (Le Breton et al., 2003). The little fire ant also causes significant economic loses related to agriculture, livestock, tourism and more. In 
Hawaii alone, it is estimated that this species results in the loss of \$549 million annually (Lee et al., 2015). Because of the ecological and economic significance of this ant, it is important to understand how it might potentially be spreading in invaded regions, like Florida. The LFA social structure is expected to influence its ability to spread rapidly, particularly in non-native regions.

One trait possessed by many successful invasive ants - including the LFA — is unicoloniality, a social structure in which workers and queens exhibit a lack of aggressiveness towards closely related non-nest mates of the same species, resulting in free movement between different nests (Eyer et al., 2018). This allows for a single supercolony to expand, unlimited by colony borders, across large geographic distances, which can lead to a high density of workers, queens, and brood that allows for increased colony survival (Eyer et al., 2018; Holway et al., 1998). Invasive ants that are known to form supercolonies include argentine ants (Linepithema humile (Mayr)), tropical fire ants (Solenopsis geminata (Fabricius)), and yellow crazy ants (Anoplolepis gracilipes (Smith, F.)), among others (Helantera et al., 2009). Greater colony success, including faster growth and reproduction, higher worker density, and larger colony size, can make it more difficult for humans to effectively control and manage ant pests (Silverman \& Brightwell, 2007). Increasing our understanding of unicolonial ants can help to inform management and monitoring techniques, which can in turn aid conservation efforts and help to reduce economic losses.

LFA is unicolonial in its non-native and parts of its native range, though not all unicolonial populations can integrate together as a single colony (Le Breton et al., 2004). Rather, in many places individual colonies have the ability to form supercolonies but remain distinct from and aggressive towards other colonies (Le Breton et al., 2004). In some cases one supercolony has become very large and dominates an entire area (Le Breton et al., 2004). For example, using behavioral assays, Le Breton et al. (2004) demonstrated LFA unicoloniality in the introduced range of New Caledonia and in the native range of Brazil. In New Caledonia, this unicoloniality was at a large scale, as ants up to $450 \mathrm{~km}$ apart showed little to no aggression toward one another other, while the Brazilian unicolonial populations were limited to a smaller scale, generally less than $3 \mathrm{~km}$ apart. This study also noted that within its native range the LFA appears to be more multicolonial as opposed to unicolonial, which means that ants of the same species form discrete bounds (Le Breton et al., 2004). This has also been documented in other invasive ant species, where unicoloniality is common in the non-native range, but occurs more rarely in the native 
regions, such as with tawny crazy ants and argentine ants (Eyer et al., 2018; Holway et al., 1998). In tawny crazy ants (Nylanderia fulva (Mayr)) this pattern may be due to a genetic bottleneck following an introduction event (Eyer et al. (2018). This might suggest that unicoloniality follows patterns of introduction events into a non-native region where a single introduction might result in unicoloniality because of reduced genetic variation among introduced individuals, whereas multiple introductions might result in reduced levels of unicoloniality because there is more genetic variation present. Understanding unicoloniality could therefore be useful as a proxy for deducing the introduction history of an ant.

Few studies have explored the behavior of the LFA worldwide, and no studies to date have explored unicoloniality using behavioral assays in Florida. The goal of this study is to determine if unicoloniality of the LFA exists in Florida, and if so, to what extent.To answer this question, this study implemented behavioral trials between colonies of LFA that utilize integration, whereby many workers interact with and show no aggressive behavior towards many workers of another colony, as a method to determine unicoloniality.

The results of this study will help clarify the social structure of the LFA populations in Florida. In turn, these results can potentially be used to improve understanding of the invasive history of the LFA in this region. If all populations sampled are found to integrate, then the ant may be acting as a single, large colony throughout the state, similarly to the population in New Caledonia. This might point to a single introduction of the species into the state. By contrast, if some populations integrate and some populations do not, then the social structure may be more similar to the population in Brazil. This may suggest multiple and even possibly ongoing introductions.

\section{Materials and Methods}

\section{Collection Sites}

Colonies of LFA were collected from three sites in Broward County, two sites in Alachua County, and one site in Palm Beach County for a total of 27 colonies from the six sites (Table 1; Figure 1). The minimum distance between sites was $2 \mathrm{~km}$ and the maximum distance was 454 $\mathrm{km}$. These locations were chosen to reflect similar distances seen in Le Breton et al. (2004) where lack of aggression was seen across these large distances suggesting large scale unicolonality. 


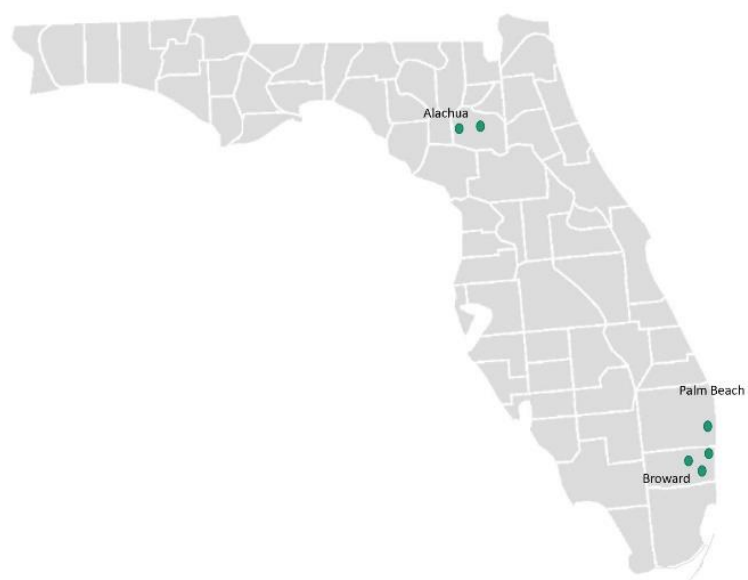

Figure 1. Map showing rough location of colony collection sites. Image courtesy of Wikimedia Commons.

Table 1. Collection Information for Each Colony.

\begin{tabular}{|c|c|c|c|c|c|c|}
\hline Kolony & Lat & Long & Location Name & City & County & Date \\
\hline $\mathrm{AC}-1.6$ & 29.6447 & -82.3623 & UF Campus: Field and Fork Garden & Gainesville & Alachua & 19-Oct-19 \\
\hline $\mathrm{AC}-1.7$ & 29.6446 & -82.3616 & UF Campus: Field and Fork Garden & Gainesville & Alachua & 19-Oct-19 \\
\hline AC-1.8 & 29.6445 & -82.3617 & UF Campus: Field and Fork Garden & Gainesville & Alachua & 19-Oct-19 \\
\hline AC-1.9 & 29.6448 & -82.3624 & UF Campus: Field and Fork Garden & Gainesville & Alachua & 19-Oct-19 \\
\hline$A C-1.10$ & 29.644635 & -82.36184 & UF Campus: Field and Fork Garden & Gainesville & Alachua & 19-Oct-19 \\
\hline AC-1.11 & 29.644635 & -82.36184 & UF Campus: Field and Fork Garden & Gainesville & Alachua & 19-Oct-19 \\
\hline AC-1.12 & 29.644762 & -82.36161 & UF Campus: Field and Fork Garden & Gainesville & Alachua & 1-Nov-19 \\
\hline AC-1.13 & 29.644736 & -82.36171 & UF Campus: Field and Fork Garden & Gainesville & Alachua & 18-Jan-20 \\
\hline AC-1.14 & 29.644736 & -82.36171 & UF Campus: Field and Fork Garden & Gainesville & Alachua & 18-Jan-20 \\
\hline$A C-2.7$ & 29.66333 & -82.40055 & Brentwood School & Gainesville & Alachua & 18-Jan-20 \\
\hline $\mathrm{AC}-2.8$ & 29.66333 & -82.40055 & Brentwood School & Gainesville & Alachua & $18-\operatorname{Jan}-20$ \\
\hline AC-2.9 & 29.66333 & -82.40002 & Brentwood School & Gainesville & Alachua & 18-Jan-20 \\
\hline BC-1.1 & 26.152587 & -80.10539 & $\begin{array}{l}\text { Hugh Taylor Birch State Recreation meditation } \\
\text { garden }\end{array}$ & Ft. Lauderdale & Broward & 27-Oct-19 \\
\hline BC-2.1 & 26.088828 & -80.17699 & Secretwoeds Pollinator Garden & Ft. Lauderdale & Broward & 27-Oct-19 \\
\hline BC- 2.2 & 26.088805 & -80.17685 & Secretwoeds Pollinator Gardens & $\mathrm{Ft}$. Lauderdale & Broward & 27-Oct-19 \\
\hline $\mathrm{BC}-2.3$ & 26.089633 & -80.17709 & Secretwoods Laurel Oak Trail & Ft. Lauderdale & Broward & 27-Oct-19 \\
\hline BC- 2.4 & 26.0891 & -80.1769 & Secretwoods Laurel Oak Trail & Ft. Lauderdale & Broward & 2-Jan-20 \\
\hline BC- 2.5 & 26.0891 & -80.1769 & Secretwoods Laurel Oak Trail & Ft. Lauderdale & Broward & 2-Jan-20 \\
\hline BC-2.7 & 26.0887 & -80.1681 & Secretwoods Pollinator Garden & $\mathrm{Ft}$. Lauderdale & Broward & 2-Jan-20 \\
\hline BC-3.1 & 26.172542 & -80.16217 & Easterlin Park & Ft. Lauderdale & Broward & 27-Oct-19 \\
\hline BC-3.2 & 26.172435 & -80.16216 & Easterlin Park & $\mathrm{Ft}$. Lauderdale & Broward & 27-Oct-19 \\
\hline BC-3.4 & 26.172 & -80.1622 & Easterlin Park & $\mathrm{Ft}$. Lauderdale & Broward & 2-Jan-20 \\
\hline BC- -3.5 & 26.172 & -80.1622 & Easterlin Park & $\mathrm{Ft}$. Lauderdale & Broward & 2-Jan-20 \\
\hline BC-3.6 & 26.1723 & -80.1612 & Easterlin Park & Ft. Lauderdale & Broward & 2-Jan-20 \\
\hline PC-1.1 & 26.667615 & -80.16811 & Qkeebeelee park nature center & $\begin{array}{l}\text { West Palm } \\
\text { Beach }\end{array}$ & $\begin{array}{l}\text { Palm } \\
\text { Beach }\end{array}$ & 28-Oct-19 \\
\hline PC-1.2 & 26.6676 & -80.1681 & Qkeeheelee park nature center & $\begin{array}{l}\text { West Palm } \\
\text { Beach }\end{array}$ & $\begin{array}{l}\text { Palm } \\
\text { Beach }\end{array}$ & 2-Jan-20 \\
\hline PC-1.3 & 26.6676 & -80.1682 & Qkeeheelee park nature center & $\begin{array}{l}\text { West Palm } \\
\text { Beach }\end{array}$ & $\begin{array}{l}\text { Palm } \\
\text { Beach }\end{array}$ & 2-Jan-20 \\
\hline
\end{tabular}




\section{Integration Trials}

To test for unicoloniality, 42 integration trials were run using the 27 colonies. Colonies were haphazardly paired to maximize the number of times that two sites were placed together. About 20 workers from two different colonies were placed together for 24 hours in an arena, a $4 \mathrm{~cm} \mathrm{x}$ $12 \mathrm{~cm}$ x $5 \mathrm{~cm}$ container with fluon-coated walls and air flow holes in the lid. Workers were differentiated by painting individual ants with enamel paint prior to the start of the trial (Figure 2). Following the 24-hour period, the ants were evaluated to determine if integration had occurred. Integration was defined as workers from the two colonies clumping together and freely interacting with one another with no aggression (Figure 3A). Lack of integration was determined by two distinct clumps of workers (painted and non-painted) and/or if the workers from the different colonies were observed engaging in aggressive behavior (e.g., biting at each other, stinging, etc.) (Figure 3B).

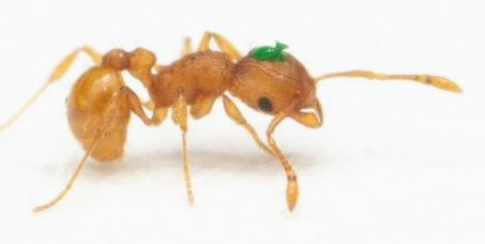

VR Seagal 2020

Figure 2. Little fire ant with a drop of green paint used to differentiate it from another colony. Photo courtesy of V.R. Seagal.

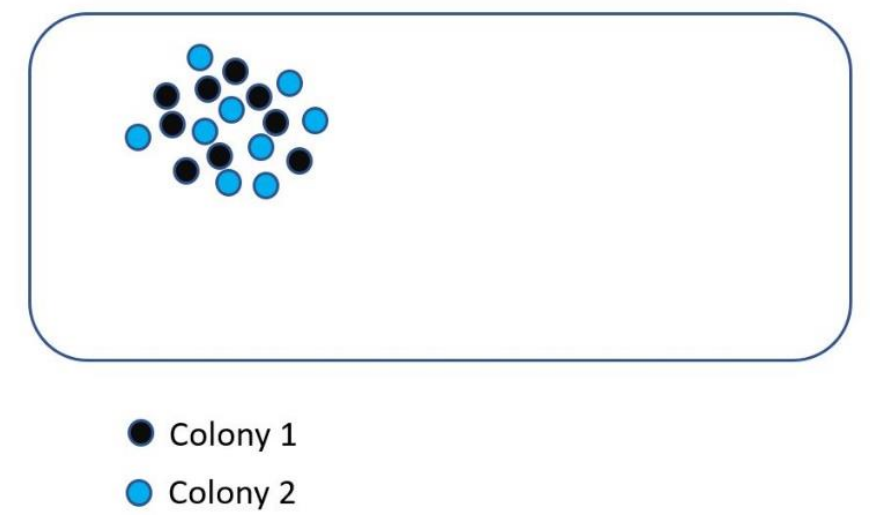

Figure 3A. Expected outcome of behavioral trial when ants integrate, suggesting unicoloniality. (Not to scale) 


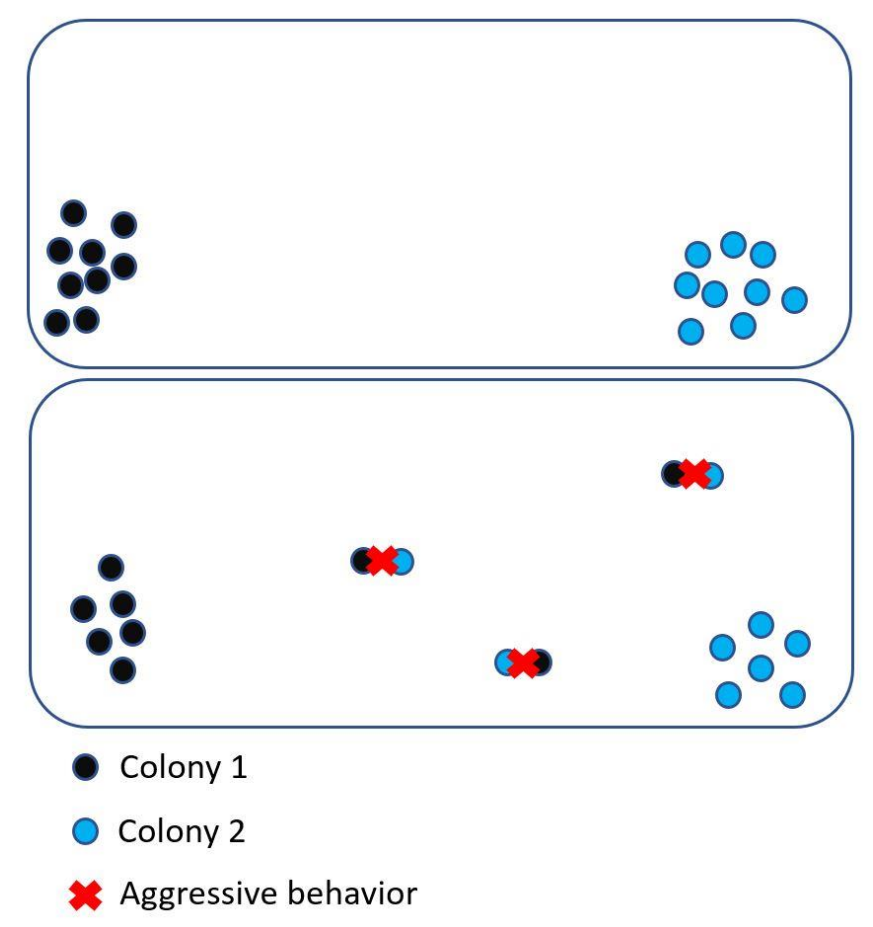

Figure 3B. Expected outcome of behavioral trial in the absence of integration, suggesting lack of unicoloniality. (Not to scale)

\section{Results}

Of 42 total integration trials, 17 pairings resulted in integration (40\%) and 25 did not (60\%), (Figure 4, Table 2). Each site pairing had consistent behavior, with sites that integrated once consistently integrating and the same being true for non-integration. The 17 pairings that did integrated were from sites no more than $10 \mathrm{~km}$ apart, while the 25 sites that did not integrated were from sites farther than $10 \mathrm{~km}$ apart. (Figure 5).

North Florida

South Florida

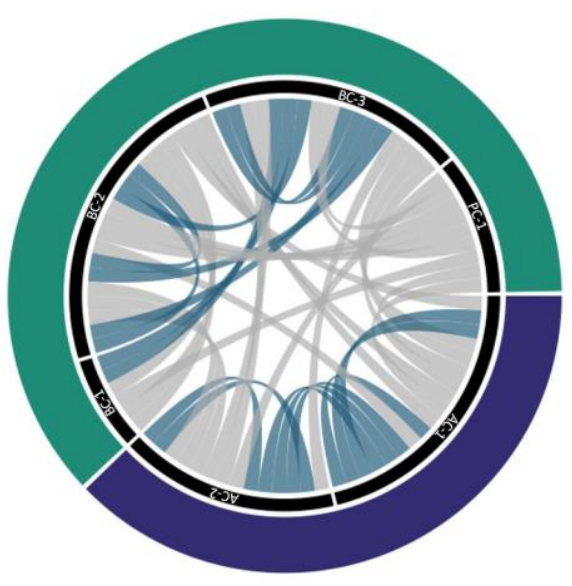

Integration

No Intergation

Figure 4. Integration trial results. Each line represents a behavioral trial: blue lines represent integration and gray lines represent no integration. 
Table 2. Integration trial pairings and results.

\begin{tabular}{ccccccc}
\hline Site name & AC-1 & AC-2 & PC-1 & BC-1 & BC-2 & BC-3 \\
\hline AC-1 & $\mathbf{3}(0)$ & $\mathbf{3}(4)$ & $\mathbf{2}(394)$ & $\mathbf{X}$ & $\mathbf{4}(448)$ & $\mathbf{3}(441)$ \\
AC-2 & & $\mathbf{2}(0)$ & $\mathbf{1}(397)$ & $\mathbf{X}$ & $\mathbf{3}(452)$ & $\mathbf{3}(445)$ \\
PC-1 & & & $\mathbf{X}$ & $\mathbf{1}(57)$ & $\mathbf{3}(64)$ & $\mathbf{2}(55)$ \\
BC-1 & & & & $\mathbf{X}$ & $\mathbf{3}(10)$ & $\mathbf{2}(6)$ \\
BC-2 & & & & & $\mathbf{2}(0)$ & $\mathbf{3}(9)$ \\
BC-3 & & & & & & $\mathbf{2}(0)$ \\
\hline
\end{tabular}

Note: Numbers represent the number of times a site was paired together in trials, the number in parentheses indicate the distance (rounded to nearest $\mathrm{km}$ ) between the sites. $\mathrm{X}$ indicates that no trials were run between sites. Blue cells indicate that integration always occurred, white cells indicate that integration never occurred.

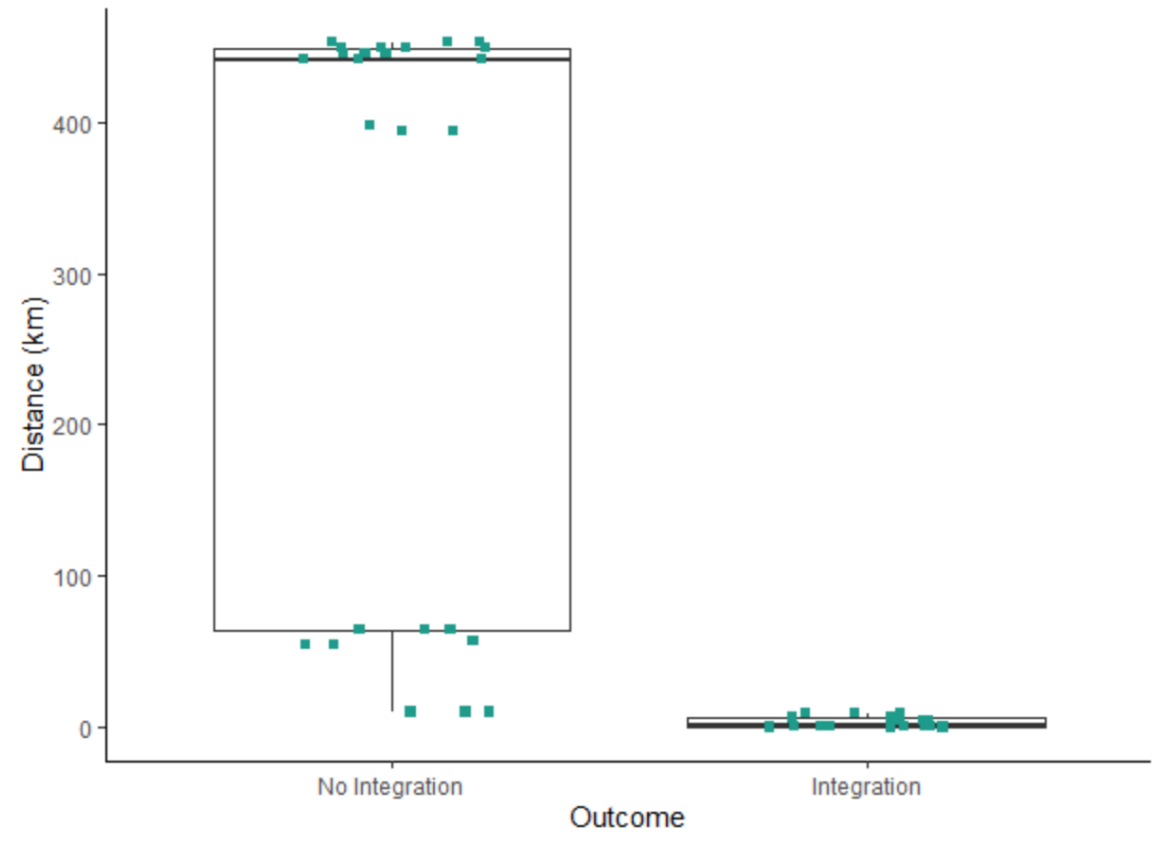

Figure 5. Boxplot showing integration trial outcomes as they varied by distance

\section{Discussion}

Behavioral integration trials revealed unicoloniality of LFA in Florida, but lack of integration across distances greater than $10 \mathrm{~km}$ suggest limitations to the scale of unicoloniality throughout the state. Because $10 \mathrm{~km}$ acted as a distance threshold by which colonies integrated in this study, this may suggest that distance is a useful tool for deducing the number of distinct unicolonial populations, though it may also be an artifact of limited sampling. The colonies that did integrate were all closer than $10 \mathrm{~km}$ apart, and their integrations may reflect either expansion of a single colony or possible human-mediated transport of ants between sites (e.g., through movement of plants or landscaping materials). As distance between colonies increases and there is less flow of 
workers, ants may see a reduction in unicoloniality, though this is unclear. Human mediated movement of ants may be significant in terms of the genetic relatedness of ants between sites, which can influence the intraspecific aggression of the ants seen there (Van Wilgenburg et al., 2010).

Genetic relatedness of LFApopulations is likely an important factor to take into consideration when exploring social structure, because closely related ants may be more likely to exhibit a lack of aggression toward eachother than ants that are not closely related (Van Wilgenburg et al., 2010). Mikheyev \& Mueller (2007) suggest that LFA lineages can be split into two main clades, with multiple introductions into non-native ranges occurring from each of these clades. Even within these clades, individuals from different introductions may be from separate genetic lineages, which then could have resulted in two or more distinct lineages within Florida. This may be the case, considering all populations sampled did not integrate with each other. Distinct colony boundaries have been documented in other unicolonial ants; Helantera et al. (2009) shows that in several other species there is an observable genetic distinction between two different supercolonies of the same species. This supports the idea that Florida may have more than one unicolonial lineage of the LFA .

These results provide insight into the unicoloniality of LFA in Florida. Despite the small sample size employed in this study, we can infer that there may have been multiple introductions of the LFA into the state, since we did not see large scale integration but rather smaller pockets of it within north and south Florida. This can also help to inform control methods of the LFA in the state. Since they do not seem to exhibit large scale unicoloniality, control efforts might use this information to be able to effectively target smaller populations and prevent spread of these smaller unicolonial pockets.

It is important to note that this study was limited in the number of sites used and the number of colonies collected and using more sites from different locations (e.g., central or south west Florida) may have revealed a different pattern of LFA social structure in the state. As such, future studies might benefit from including more sites from more locations throughout Florida. Additionally, because genetic tools were not used to determine relatedness, future studies would benefit from incorporating genetic data with behavioral data. Research should continue to explore LFA social structure to gain a better understanding of the ant, its ecological and economic impact, and how it can be monitored and managed. 


\section{Acknowledgments}

We thank the Center for Undergraduate Research for providing funding through the University Scholars Program, all members of the Lucky Lab, Dr. Daniel Hahn and Dr. Anthony Auletta for providing support, guidance, and mentorship in preparing and completing this project, and Dr. Doug Booher for providing guidance in creating a protocol.

\section{References}

Eyer, P., McDowell, B., Johnson, L. N. L., Calcaterra, L. A., Fernandez, M. B., Shoemaker, D., Puckett, R. T., \& Vargo, E. L. (2018). Supercolonial structure of invasive populations of the tawny crazy ant Nylanderia fulva in the US. BMC Evolutionary Biology, 18(1), 209. https://doi.org/10.1186/s12862-018-1336-5

Helantera, H., Strassmann, J. E., Carillo, J., \& Queller, D. C. (2009). Unicolonial ants: where do they come from, what are they and where are they going. Trends in Ecology and Evolution, 24(6), 341-349. https://doi.org/10.1016/j.tree.2009.01.013

Holway, D. A., Suarez, A. V., \& Case, T. J. (1998). Loss of intraspecific aggression in the success of a widespread invasive social insect. Science, 282(5390), 949-952.

https://doi.org/10.1126/science.282.5390.949

Le Breton, J., Chazeau, J., \& Jourdan, H. (2003). Immediate impacts of invasion by Wasmannia auropunctata (Hymenoptera: Formicidae) on native litter ant fauna in a New Caledonian rainforest. Austral Ecology, 28(2), 204-209. https://doi.org/10.1046/j.1442-9993.2003.01266.x

Le Breton, J., Delabie, J. H. C., Chazeau, J., Dejean, A., \& Jourdan, H. (2004). Experimental evidence of large-scale unicoloniality in the tramp ant Wasmannia auropunctata (Roger). Journal of Insect Behavior, 17(2), 263-271. https://doi.org/10.1023/B:JOIR.0000028575.28700.71

Lee, D. J., Motoki, M., Vanderwoude, C., Nakamoto, S. T., \& Leung, P. (2015). Taking the sting out of little fire ant in Hawaii Ecological Economics, 111, 100-110 https://doi.org/10.1016/j.ecolecon.2015.01.010

Mikheyev, A. S., \& Mueller, U. G. (2007). Genetic relationships between native and introduced populations of the little fire ant Wasmannia auropunctata. Diversity and Distributions, 13(5), 573-579. https://doi.org/10.1111/j.1472-4642.2007.00370.x

Silverman, J., \& Brightwell, R.J. (2008). The Argentine ant: challenges in managing an invasive unicolonial pest. Annual Review of Entomology, 53(1), 231-252. https://doi.org/10.1146/annurev.ento.53.103106.093450

Van Wilgenburg, E., Torres, C.W., \& Tsutsui, N.D. (2010) The global expansion of a single ant supercolony. Evolutionary Applications, 3(2), 136-143. https://doi.org/10.1111/j.17524571.2009.00114.x

Wetterer, J. K. (2013). Worldwide spread of the little fire ant, Wasmannia auropunctata (Hymenoptera: Formicidae). Terrestrial Arthropod Reviews, 6(3), 173-184. https://doi.org/10.1163/1874983606001068 